\title{
Cardiac risk stratification: Role of the coronary calcium score
}

This article was published in the following Dove Press journal:

Vascular Health and Risk Management

10 July 2010

Number of times this article has been viewed

\author{
Rakesh K Sharma' \\ Rajiv K Sharma' \\ Donald J Voelker' \\ Vibhuti N Singh ${ }^{2}$ \\ Deepak Pahuja ${ }^{3}$ \\ Teresa Nash' \\ Hanumanth K Reddy' \\ 'Medical Center of South Arkansas, \\ University of Arkansas for Medical \\ Sciences, Little Rock, AR, USA; \\ ${ }^{2}$ Bayfront Medical Center, \\ St Petersburg, Florida; ${ }^{3}$ Saint Vincent \\ Health Center, Erie, PA, USA
}

\begin{abstract}
Coronary artery calcium (CAC) is an integral part of atherosclerotic coronary heart disease (CHD). CHD is the leading cause of death in industrialized nations and there is a constant effort to develop preventative strategies. The emphasis is on risk stratification and primary risk prevention in asymptomatic patients to decrease cardiovascular mortality and morbidity. The Framingham Risk Score predicts CHD events only moderately well where family history is not included as a risk factor. There has been an exploration for new tests for better risk stratification and risk factor modification. While the Framingham Risk Score, European Systematic Coronary Risk Evaluation Project, and European Prospective Cardiovascular Munster study remain excellent tools for risk factor modification, the CAC score may have additional benefit in risk assessment. There have been several studies supporting the role of CAC score for prediction of myocardial infarction and cardiovascular mortality. It has been shown to have great scope in risk stratification of asymptomatic patients in the emergency room. Additionally, it may help in assessment of progression or regression of coronary artery disease. Furthermore, the CAC score may help differentiate ischemic from nonischemic cardiomyopathy.
\end{abstract}

Keywords: coronary calcium scoring, coronary artery disease, CAC, cardiomyopathy, angiography, chest pain, Framingham, risk stratification, risk factors

\section{Background}

Coronary heart disease (CHD) is the leading cause of death in industrialized countries. Cardiovascular mortality in the US alone is close to a million per year. This problem is on the rise, in view of the increasing number of elderly people in the US and worldwide. By 2020, there will be more than 50 million people aged older than 65 years in the US alone. Continuous efforts are being made to develop preventative strategies for CHD. Cardiovascular risk stratification by primary risk assessment is a key step towards this goal. Traditional risk assessment is based on the Framingham Risk Score (FRS) which was developed based on clinical research in men and women from Framingham, Massachusetts, followed over three generations. This evaluation was done to understand better the causes of cardiovascular disease. There have been at least 1973 publications in peer-reviewed journals up until 2008. This has led to risk factor stratification and modification measures in cardiovascular practice. This risk stratification is based on the Framingham Heart Study (FHS, see http://www.framinghamheartstudy.org) in the US, the European Systematic Coronary Risk Evaluation (SCORE) study, ${ }^{1}$ and the Prospective Cardiovascular Munster (PROCAM) study in Germany. ${ }^{2}$ Each of these studies documents a 10-year risk for cardiovascular events which dictates public
Correspondence: Rakesh K Sharma 700 West Grove Street, El Dorado, AR 7I730, USA

Tel + I 8708755540

Fax +l 8708755548

Email rk1965@gmail.com,

rsharma@uams.edu 
policies, and the intensity of treatment generally depends upon the risk stratification.

\section{Cardiac risk assessment}

Unfortunately, traditional risk factor assessment has a very poor sensitivity and specificity to predict coronary events. In the past, exercise stress testing was performed to diagnose coronary artery disease (CAD) in asymptomatic patients and it is not currently recommended as a screening test. ${ }^{3}$ At least $25 \%$ of patients with CHD have asymptomatic presentation with nonfatal myocardial infarction (MI) or sudden death, and therefore there is a constant need for improvement of risk stratification measures. ${ }^{4}$ The American Heart Association (AHA) Prevention V Conference emphasized going beyond secondary prevention and addressed ways to identify risk in asymptomatic patients to justify more intensive risk reduction. $^{5}$

It is common to address this clinical risk assessment as an initial step and also recognize CHD risk equivalents, as shown in Tables 1 and 2. National Cholesterol Education Program (NCEP) guidelines have classified patients into different categories, depending upon the presence of CHD or risk factors for 10-year risk of fatal CHD or nonfatal MI, as illustrated in Table 3.

The NCEP targets high-risk groups for risk factor modification, and intermediate-risk groups may need further risk stratification. Furthermore, intermediate-risk groups may be deemed to be high-risk based on the presence of coronary artery calcium (CAC) requiring aggressive intervention. Several investigators have investigated use of the CAC score

Table I Risk factors contributing to I0-year risk of CHD

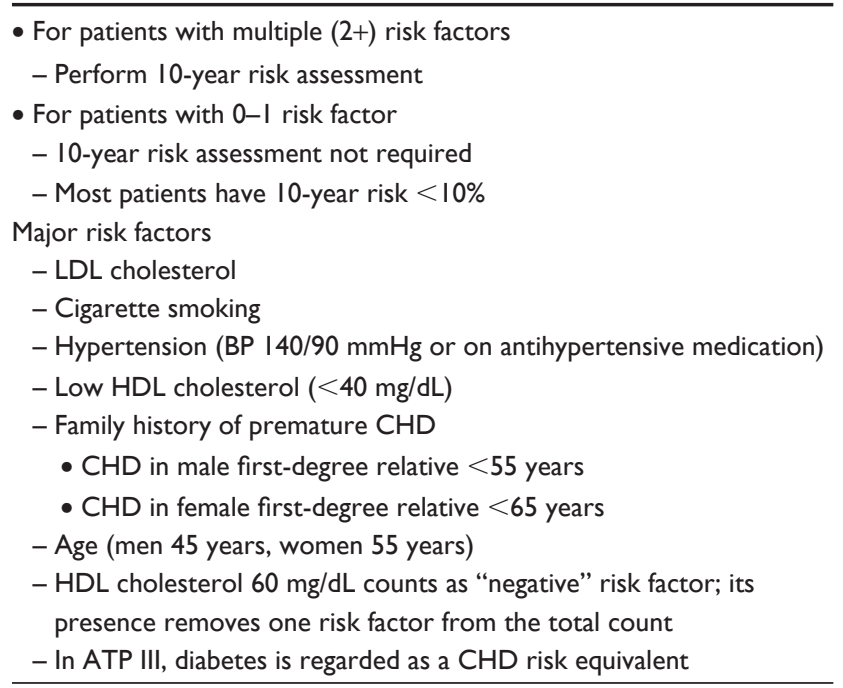

Abbreviations: ATP III, Adult Treatment Panel III; CHD, coronary heart disease; $H D L$, high-density lipoprotein; LDL, low-density lipoprotein; BP, blood pressure.
Table 2 Coronary heart risk equivalents

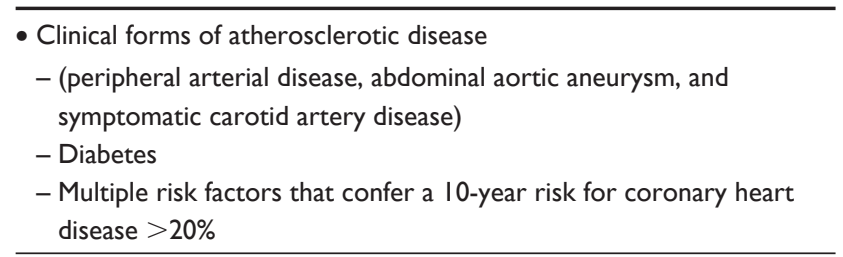

to risk stratify patients further. Current clinical practice for risk stratification is based on several clinical guidelines. ${ }^{6,7}$

Each risk factor has points, and based on their accumulated points, patients fall into categories of low-, moderate-, to highrisk groups for CHD. The risk score was developed based on risk factors such as total cholesterol, high-density lipoprotein cholesterol (HDL-C), blood pressure, age, smoking, and gender. Based on these risk factor scores, the risk for CHD can be classified from low- to high-risk, and one can estimate the 10-year likelihood of developing a major cardiac event, as shown in Table 3. Low-risk CHD correlates with 10\% mortality at 10 years, moderate-risk with $10 \%-20 \%$, and high-risk with greater than $20 \%$ risk of mortality. This can readily be calculated by using an online Framingham risk calculator at http://hp2010.nhlbihin.net/ATPiii/calculator. asp?usertype=prof; http://www.framinghamheartstudy.org/ risk/hrdcoronary.html.

\section{Framingham heart study}

The FRS uses traditional risk factors to predict risk of coronary events in people without known CAD. ${ }^{8,9}$ This cardiac risk assessment is based on the FHS, which is an ongoing study for more than 50 years leading to several publications. This historical study has participation of three generations, and a careful analysis of the initial cohort and subsequent two generations has led to identification of major cardiovascular risk factors. This had led to the achievement of several milestones in the management of cardiovascular disease. One of the milestones achieved in 1998 was risk prediction, with an algorithm based on the presence of various risk factors. There have been numerous discussions on FRS

Table 3 Framingham risk score

- Risk score $>20 \%$ : High-risk range, with a greater than $20 \%$ risk of heart attack or death from coronary disease in the next 10 years. This risk can be reduced by addressing the risk factors

- Risk score 10\%-20\%: Intermediate-risk range, with a 10\%-20\% risk of heart attack or death from coronary disease in the next 10 years. This risk can be reduced

- Risk score < 10\%: Low-risk range, with less than 10\% risk of heart attack or death from coronary disease in the next 10 years 
calculation on risk assessment in asymptomatic patients which can be found on the Framingham website and the National Heart Lung and Blood Institute websites. The risk score classifies patients into high-risk, intermediate-risk, and low-risk for CHD, as shown in Table 3.

\section{European PROCAM study}

In the US, the FHS provides the extensively validated risk assessment by a multivariable scoring system for major cardiovascular endpoints. This scoring system includes major risk factors such as age, gender, total cholesterol, HDL-C, hypertension (or on treatment for hypertension), and cigarette smoking. While family history was not included as a risk factor in FHS, other studies, ie, SCORE and PROCAM, ${ }^{1,2}$ have included age, gender, low-density lipoprotein cholesterol (LDL-C), HDL-C, triglycerides, systolic blood pressure (BP), cigarette smoking, family history of premature $\mathrm{CHD}$, and presence or absence of diabetes mellitus. PROCAM was a large epidemiological cohort study, developed from data for more than 26,000 subjects in Germany over a period of 25 years ${ }^{2}$ which helped to develop a cardiovascular risk calculator. Risk can be calculated on the PROCAM website by a simplified version of the PROCAM risk calculator, which is an International Task Force for Prevention of Coronary Heart disease (http://www.chd-taskforce.com/procam_interactive.html).

\section{European SCORE study}

SCORE was developed for cardiovascular risk stratification in European clinical practice to calculate the 10-year risk for CHD and noncoronary cardiovascular disease. This score system was based on data collected from a large cohort of 205,178 subjects from 12 European countries. ${ }^{1}$

\section{WHO MONICA project}

The concept of risk stratification was born after the FHS. There was a need for long-term monitoring of mortality, morbidity, and risk factors in clinical practice. The Multinational Monitoring of Trends and Determinants in Cardiovascular Diseases (MONICA) ${ }^{10}$ project was established to monitor trends in cardiovascular disease around the world. This project showed major changes in survival, driven by changes in coronary event rates, which further emphasize the need for risk factor modification tools.

\section{Incremental risk stratification by CAC score}

While the FRS and PROCAM remain excellent tools for risk factor modification, the $\mathrm{CAC}$ score may have additional benefit in risk assessment. Atherosclerotic plaque passes through several stages of plaque rupture and healing, followed by calcification. Thus, the presence of calcium can be considered an advanced marker of CHD. There have been numerous studies supporting the role of CAC score for prediction of MI and cardiovascular death. CAC clearly adds to the predictive value of traditional risk factors. While spotty calcification has been considered a marker of vulnerable plaque, ${ }^{11}$ the relationship between the presence and amount of calcium in an individual coronary artery found on coronary angiography to predict cardiovascular events is uncertain. ${ }^{12}$ It is most likely that the co-occurrence of calcified and noncalcified plaques may determine progression of CHD. ${ }^{13}$

\section{Role of CAC score in primary prevention}

In 1996 and subsequently in 2000, AHA consensus documents ${ }^{14,15}$ have stated that "CAC is a part of development of CAD and occurs exclusively in atherosclerotic CAD and is absent in normal arteries". CAC plaque documents the presence of CAD in an individual patient as compared with just the presence of risk factors. Detection of asymptomatic CAD has been of great interest since the publication of the Screening for Heart Attack Prevention and Education (SHAPE). ${ }^{16}$ Moreover, detection of vulnerable plaque leading to coronary events is of paramount importance. The role of CAC in identification of vulnerable plaque is unknown. ${ }^{17}$ Spotty calcification has been shown to identify patients with vulnerable plaque. ${ }^{11}$ This may be due to noncalcified plaque on the shoulders of calcified plaque.

\section{CHD risk assessment with CAC score in asymptomatic patients}

The important risk factor, ie, positive family history, is not included in risk stratification by the FRS. Because FRS predicts CHD events only moderately well, there has been an exploration for better risk stratification tests so that patients may benefit from aggressive risk factor modification. ${ }^{5-7}$ This can be accomplished by CAC scoring. There have been a large number of studies showing the prognostic value of the CAC score in 2000-2009, ${ }^{18-24}$ leading to great interest in this score.

While initially there were conflicting data about the prognostic value of the CAC score, this was addressed by Arad et al in 2000 in 1172 subjects by multivariate analysis. ${ }^{25}$ The purpose of this study was to evaluate the prognostic accuracy of a high CAC score with electron-beam computed tomography (CT). During an average 3.6 year follow-up in 
this study, 39 subjects had coronary events, which included nonfatal $\mathrm{MI}$ in 15 , coronary artery revascularization in 21 , and coronary death in three. Based on these data, it was concluded that electron-beam CT predicts coronary events. Kondos et $\mathrm{al}^{26}$ also demonstrated the added value of CAC score in a largest retrospective study of 8855 self-referred men and women without prior cardiovascular events. Followup was available in 5634 (64\%) at $37 \pm 13$ months for 4151 men and 1484 women, and showed incremental prognostic information in addition to conventional risk factors.

Greenland et $\mathrm{al}^{20}$ examined the incremental prognostic value of the CAC score in addition to traditional risk factors in a prospective observational study. This was a populationbased study of 1461 asymptomatic adults with traditional coronary risk factors assessed by FRS. These participants were screened from 1990-1992 and had initial FRS and CAC scores. They were contacted yearly up to 8.5 years after the initial CAC test for nonfatal MI and/or CHD-related death. This study evaluated whether FRS and CAC score predicted all-cause mortality, which was stratified by four levels of FRS and four levels of CAC score, as illustrated in Figure 1. FRS categories are the estimated 10-year risk of CHD (death or nonfatal MI) events based on FRS. In this study, CAC score alone was able to predict CHD risk independently of FRS. Moreover, CAC score significantly modified the risk prediction in all categories of FRS category with risk $>10 \%$ (ie, 10-year risk of CHD events $>10 \%$ ).

Another large study by Lamont et $\mathrm{al}^{24}$ reported a follow-up on 11,000 patients who underwent screening medical examination including CAC score during 1995-2000. In a mean

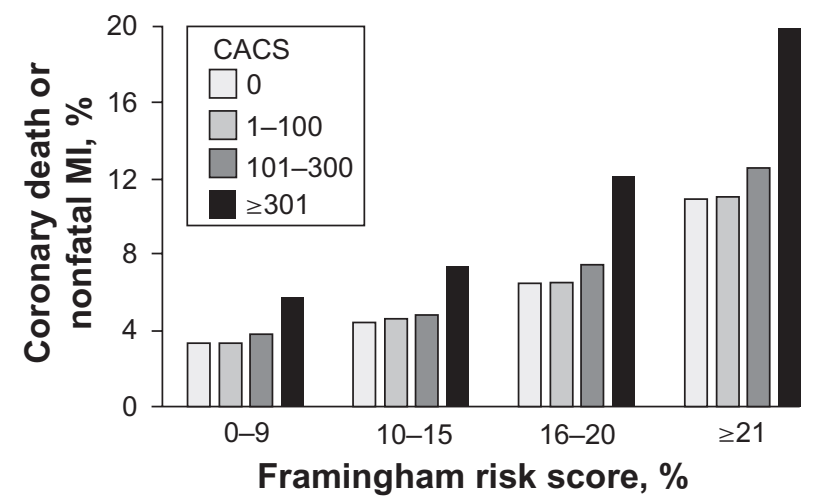

Figure I Predicted seven-year event rate from Cox regression model for CHD death or nonfatal MI for different categories of FRS or CAC score. The event rates are stratified by four levels of FRS and four different levels of calcium score. Analysis showed a statistically significant difference between and calcium score $>300$ and other groups for FRS categories > 10\% CHD risk. Copyright (C) 2004, American Medical Association. All rights reserved. Adapted with permission from Greenland P, LaBree L, Azen SP, Doherty TM, Detrano RC. Coronary artery calcium score combined with Framingham score for risk prediction in asymptomatic individuals. JAMA. 2004;291 (2):210-215.

Abbreviations: CACS, coronary artery calcium score; CHD, coronary heart disease; FRS, Framingham Risk Score; MI, myocardial infarction. follow-up of 3.5 years in asymptomatic men and women, CHD events (nonfatal MI and CHD-related deaths) were higher with a CAC score $>400$. The Prospective Army Coronary Calcium Project (PACC) 22 showed the independent prognostic value of CAC score in young asymptomatic men and women of mean age 43 years. This study showed that the presence of CAC was associated with an 11.8-fold increased risk of coronary events in a three-year follow-up of men aged 40-45 years.

The Rotterdam Coronary Calcification $\mathrm{Study}^{23}$ addressed the role of the CAC score in elderly patients. This was a prospective, population-based study in 1795 patients comparing patients with CAC $<100$ with those having CAC of 101-400, CAC 401-1000, and CAC >1000. CAC score was found to be a strong and independent predictor of future events, as illustrated in Figures 2 and 3. Different CAC score categories also predicted survival free of a CHD event and cardiovascular disease events, as shown in Figure 3.
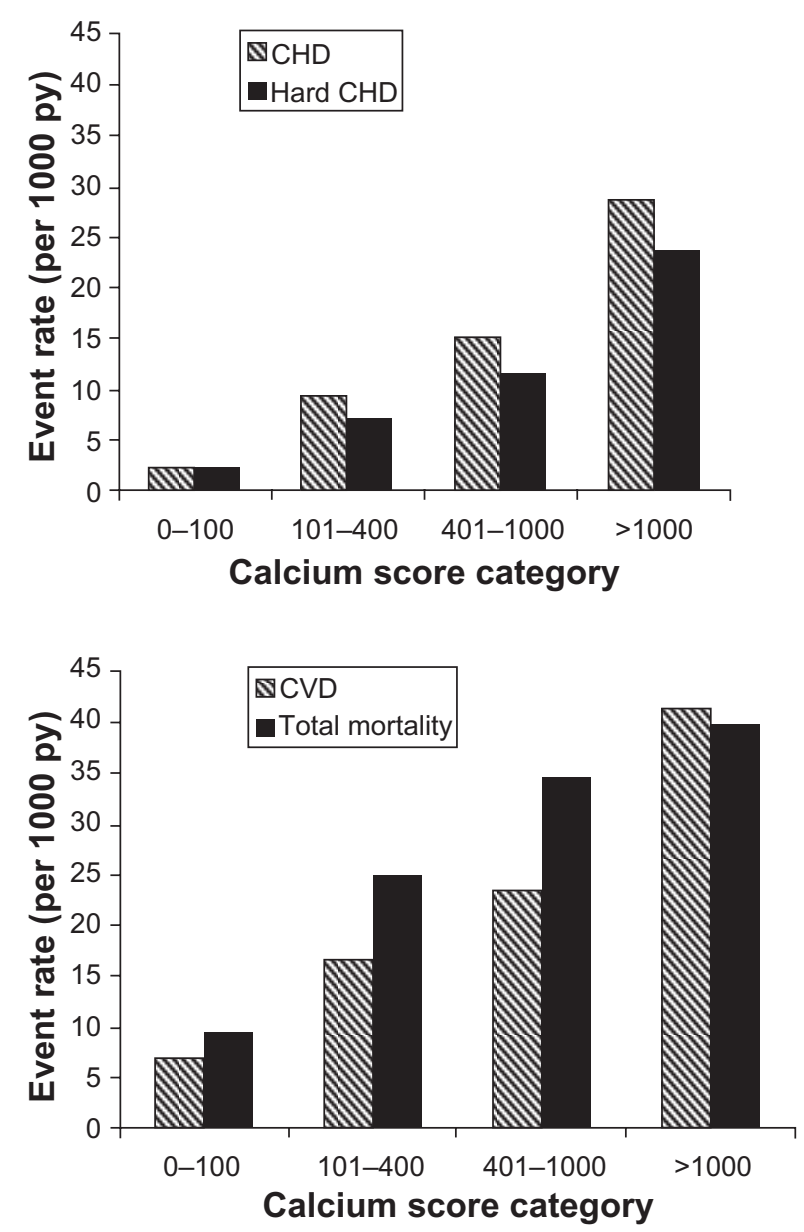

Figure 2 Event rate according to calcium score category. Copyright (C) 2005, American Heart Association. All rights reserved. Adapted with permission from Vliegenthart R, Oudkerk M, Hotman A, et al. Coronary calcification improves cardiovascular risk prediction in the elderly. Circulation. 2005; I 12(4):572-577.

Abbreviations: CVD, cardiovascular disease; CHD, coronary heart disease; FRS, Framingham Risk Score. 


\section{A}
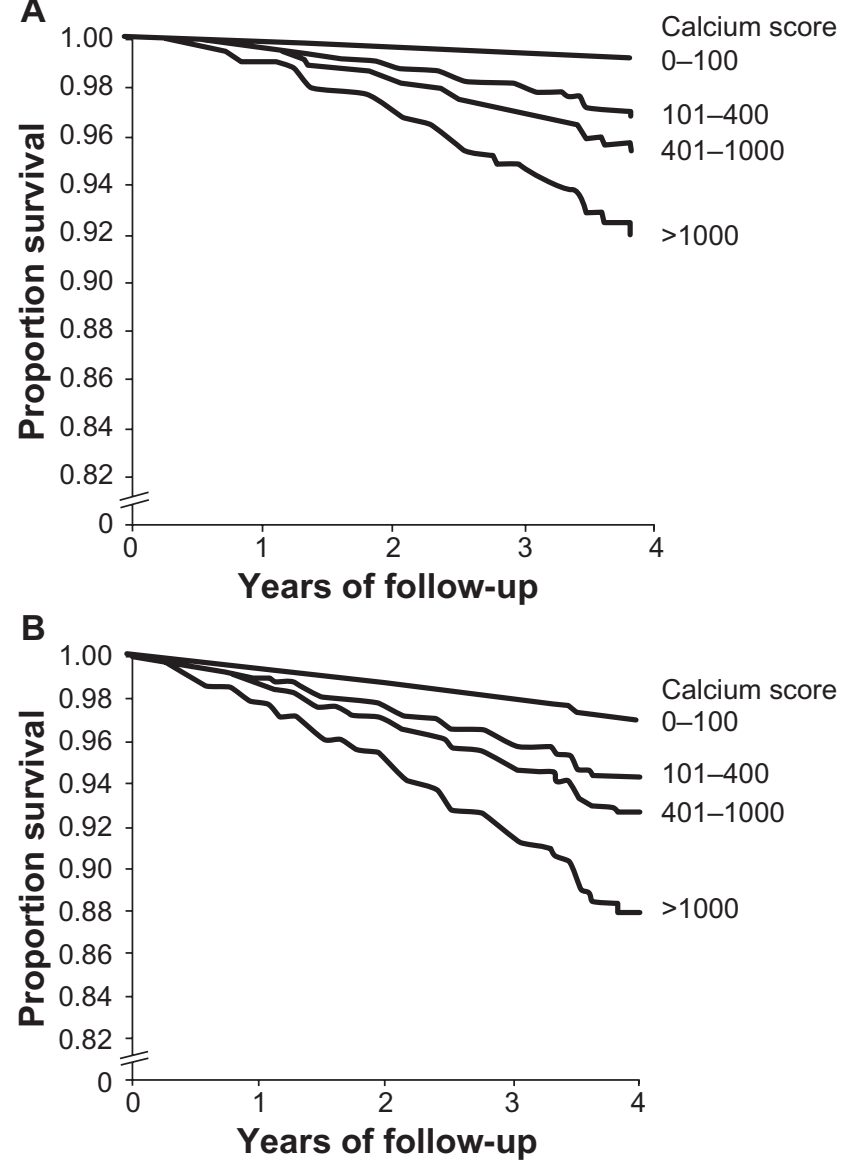

Figure 3 Survival curves, free of CHD A) and CVD B) events, according to calcium score.Copyright (c) 2005, American Heart Association. All rights reserved. Adapted with permission from Ehara S, Kobayashi Y, Yoshiyama M, et al. Circulation. 2005; I 12 : 572-577.

Abbreviations: CHD, coronary heart disease; CVD, cardovascular disease.

Bild et $\mathrm{al}^{27}$ showed that $\mathrm{CAC}$ is influenced by age, gender, and ethnicity. The role of CAC score in different ethnic groups for incremental risk prediction was examined in the MultiEthnic Study of Atherosclerosis (MESA).$^{28}$ MESA was a population-based study which enrolled subjects of four different ethnic groups from six sites across the US. Data on CHD risk factors and CAC scores in different ethnic groups were followed for an average period of 3.8 years. Patients had comprehensive risk assessment with every possible test and were followed from 2000 onwards. This study showed that doubling of CAC score increased the risk of a major cardiovascular event, such as death and MI. Risk of any coronary events or major events was independent of other risk factors. CAC score was found to be highly predictive of cardiovascular risk in all the four ethnic groups and it contributed to the risk of both major coronary events (Figure 4, Panel A) and any coronary events (Figure 4, Panel B). CAC score alone was better than all the other risk factors combined for risk prediction.
This clearly demonstrated that CAC score is a strong predictor for the risk of developing clinical CHD. It provides a risk prediction beyond the standard risk prediction of the FRS. This risk prediction by CAC scoring was also demonstrated in different ethnic groups, including white, black, Hispanic, and Chinese in the MESA trial. Based on this study, there is a risk calculator based on age, gender, ethnicity and other risk factors, known as the MESA risk calculator, where an individual's CAD risk can be calculated relative to that of peers (http://www.mesa-nhlbi.org/Calcium/ input.aspx).

\section{Role of CAC in symptomatic patients}

In symptomatic patients, the CAC score has been evaluated as a noninvasive tool to diagnose obstructive $\mathrm{CAD}$, and this was published as an ACC/AHA consensus document. ${ }^{29,30}$

A

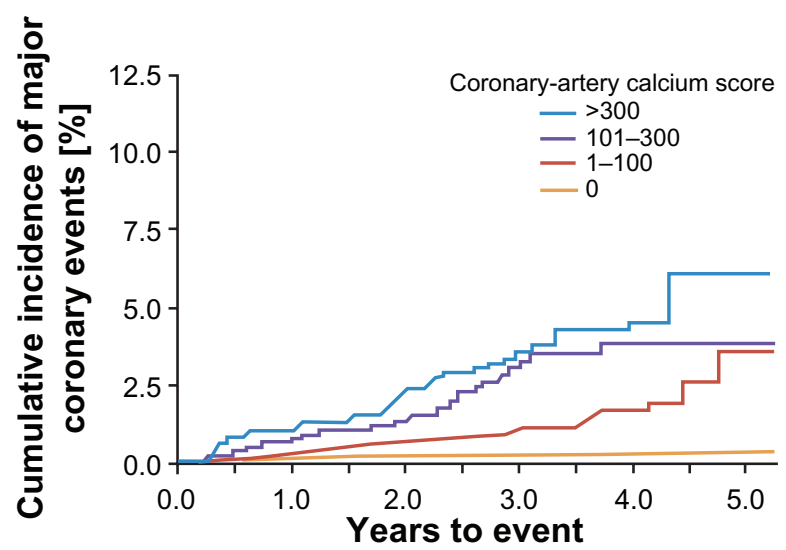

B

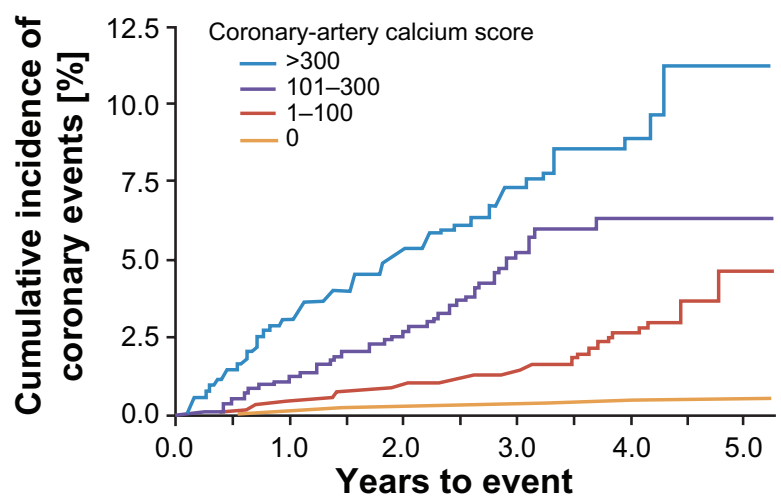

Figure 4 Unadjusted Kaplan-Meier cumulative event curve for coronary events among participants with calcium score $0,1-100,101-300$, and $>300$. Panel A shows the rate of major coronary events ( $\mathrm{Ml}$ and death from $\mathrm{CHD}$ ); Panel $\mathbf{B}$ shows the rates for any coronary event. Differences between all curves are statistically significant. Copyright (C) 2008, Massachusetts Medical Society. All right reserved. Adapted with permission from Detrano R, Guerci AD, Carr JJ, et al. N Engl J Med. 2008:358 1336-1345. 
This document examined 3683 symptomatic patients in 16 studies for evaluation of diagnostic accuracy of CAC scoring in patients referred for cardiac catheterization. Higher CAC score increased the likelihood of detecting significant CAD with greater than $50 \%$ stenosis. Guerci et $\mathrm{al}^{31}$ showed the relationship of CAC score to CAD in 290 symptomatic patients undergoing cardiac catheterization for approved clinical indications. A CAC score of 80 was not associated with any likelihood of CAD, regardless of number of risk factors and a CAC of 170 or more was associated with an increased likelihood of obstructive CAD $(P<0.001)$. Similarly, Kennedy et al have shown that CAC score had a correlation with the extent of CAD, and was found be a better discriminator than other risk factors. A substudy from the MESA cohort analyzed the relationship between extent of CAC and severity of stenosis, and showed a significant association between the extent of CAC and mean degree of stenosis in individual coronary vessels. ${ }^{32}$ Schmermund et $\mathrm{al}^{33}$ also showed the CAC score to be a better discriminator which improved diagnostic accuracy over conventional risk factors. A multicenter trial in 1851 patients reported the role of ultrafast CT for diagnosis of CAD in symptomatic patients who underwent cardiac catheterization. In this study, a CAC score of 80 or more had a sensitivity of $79 \%$ and specificity of $72 \%,{ }^{34}$ whereas the other large study ${ }^{35}$ used a cutoff CAC score of 100 , leading to improved sensitivity of $95 \%$ and specificity of $79 \% .{ }^{35}$ Nieman et $\mathrm{al}^{36}$ investigated the value of CAC detection on CT coronary angiography in comparison with exercise testing and CT coronary angiography to detect obstructive CAD. This study showed that lack of coronary calcium was a reliable means to exclude obstructive CAD. ${ }^{36}$

\section{Role of CAC score in the emergency room}

Absence of CAC or minimal CAC predicted a very low incidence of future cardiac events in asymptomatic patients, ${ }^{18,25,37,38}$ symptomatic patients, and symptomatic patients undergoing cardiac catheterization. ${ }^{39,40}$ Several studies have shown the value of the CAC score in emergency room (ER) patients with a negative electrocardiogram (ECG) and negative cardiac enzymes as a triage tool with a very high negative predictive value. ${ }^{41,42}$ Georgiou et $\mathrm{al}^{42}$ performed electron beam CT in 192 patients with chest pain and then followed them up for $50 \pm 10$ months. Among this cohort, 30\% showed a graded relationship between all cardiac events and CAC score. This study showed that CAC score used as a triage test had a sensitivity of $97 \%$ and a negative predictive value of $99 \%$. Patients without CAC (zero score) had a 0.6/year future cardiovascular event rate. Furthermore, recent studies have shown that CAC score may be a useful tool in the ER for risk stratification of patients with an acute coronary syndrome. Several other studies have demonstrated a significant correlation between CAC score and overall coronary artery atherosclerotic plaque, with a high sensitivity $>95 \%$ and a high negative predictive value of $>95 \%$. $^{13,43-45}$

\section{Role of CAC score in triage of chest pain}

Several studies have shown that CAC score may be a rapid and effective triage tool in ER patients with chest pain and nonspecific ECG abnormalities. ${ }^{41,42}$ The high sensitivity and high negative predictive value of the CAC score may allow early discharge of such patients. One study with longterm follow-up showed that a CAC of zero represented a very low risk for cardiovascular events. ${ }^{42}$ Therefore, absence of CAC may be used as an effective screening tool before undertaking invasive coronary angiography. A CAC score of less than 100 predicts a low risk, with a less than $2 \%$ chance of an abnormal perfusion nuclear study, ${ }^{46,47}$ and a less than $3 \%$ probability of obstructive CAD. ${ }^{34,35}$

\section{CAC score to evaluate progression or regression}

Does modulation of cardiac risk factors translate into regression of CAC score? Pathological studies have showed that a positive CAC score represents calcium in plaque which is an end result of healing of ruptured plaque. The process is complex, and drug therapy may have the potential to alter this fundamental process of calcification in the progression of atherosclerotic plaque. There are several factors in the progression of CAD, and the CAC score may be of biologic relevance. Serial CAC scoring may help monitor plaque regression by medical therapy. ${ }^{48}$ One needs to be mindful about the intertest variability in CAC score and have confidence in this to monitor regression or progression. Many studies have shown interscan variability of CAC score by $25 \%-50 \%,{ }^{49-51}$ but using the same protocol this can be reduced to $10 \%-15 \% .{ }^{51,52}$ Given that the annual progression of CAC is about $20 \%,{ }^{49-51}$ the standard protocol will allow the detection of progression. This may have a bearing on management of the intermediate-risk group category with a high CAC score.

Several reports have shown CAC progression associated with increased risk of cardiovascular events and a stable $\mathrm{CAC}$ score associated with lower risk of cardiovascular 
events. ${ }^{19,53,54}$ In the presence of definite CAC score progression $(>15 \%)$ there was a significant relative risk of $\mathrm{MI}$ compared with patients having a stable score. Based on these findings, a serial CAC score is an attractive strategy for monitoring progression or regression of CAD. CAC regression has been demonstrated with pharmacologic interventions such as statins. ${ }^{55}$ Due to both cost issues and radiation concerns, serial monitoring of progression or regression of CAD using CAC scoring is not recommended at this time.

\section{CAC score in diagnosis of cardiomyopathy}

Technical ease and standardization of CAC score may play a role in the evaluation of the etiology of cardiomyopathy. Clinical manifestations of ischemic and nonischemic cardiomyopathy are similar and often require invasive testing, such as cardiac catheterization for final diagnosis. The role of electron beam CT was tested in a prospective, double-blind study ${ }^{56}$ with a $99 \%$ sensitivity for ischemic cardiomyopathy. The specificity for nonischemic cardiomyopathy was $92 \%$ for a CAC score of $<80 \%$ and $83 \%$ for a CAC score of zero.

\section{Technique and radiation issues}

Radiographically, CAC provides an estimate of CAD burden. The most frequently used measure of CAC in the literature is the Agatston score ${ }^{57}$ which measures the amount of calcium in each lesion. Total CAC is the sum of the scores of all the calcified lesions in all the vessels.

This could be done with electron-beam CT or multi-detector $\mathrm{CT}$ available in most hospitals. There is no difference in CAC measured by electron-beam CT or multi-detector $\mathrm{CT}{ }^{58} \mathrm{~A}$ stack of cardiac images are obtained in an axial mode and calcified plaque is identified. This calcified plaque image is seen as white dots which are picture elements or pixels with an underlying number called Hounsfield Units (HU). Based on the HU numbers assigned to a pixel and its volume, we arrive at a CAC score. Just like a value for hypertension, a HU value above 129 is considered dense enough to call it calcified and a weight factor is assigned, based on this number, to quantify the density. It is a simple procedure whereby the patient is brought into the room, placed in the scanner, and the whole heart is scanned. The patient goes through few breathing exercises and there is no need to have heart rate control for the test. Images with a slice thickness of $2.5 \mathrm{~mm}$ are obtained with either triggered or prospective ECG gating. With the prospective gating the radiation is as low as 1 milliSievert (mSv).

\section{Radiation exposure}

Radiation exposure during CAC scoring is as low as 1.0-1.3 $\mathrm{mSv}$ with electron-beam $\mathrm{CT}^{59}$ and $3 \mathrm{mSv}$ with multi-detector CT using retrospective gated scanning, which could be reduced to $1 \mathrm{mSv}$ in prospective gating by multidetector $\mathrm{CT} .{ }^{60}$ Any amount of radiation should be a concern and the "as low as reasonably achievable" (ALARA) principle should be used. This fact is underscored by a recent publication whereby current CT scan use for various studies is expected to contribute to a large number of future malignancies, which were estimated to be up to 29,000 on the basis of all the CT scans done in $2007 .{ }^{61}$ Given the carcinogenic potential of radiation, health care workers who prescribe it must be fully aware of radiation risks. They should have a full understanding of the effective dose concept which is a standard of measure of exposure expressed in $\mathrm{mSv}$. Effective dose is the sum of weighted equivalent doses in all the organs and tissues during a particular scan. Due to higher doses delivered to lungs and female breast in coronary CT angiography, there is a higher carcinogenic effect on these organs. This risk is higher in younger patients and more in women than in men.

\section{Summary}

CAC is an integral part of development of CAD. Therefore, CAC scoring may be a valuable noninvasive imaging modality to do cardiac risk stratification in asymptomatic patients for cardiovascular risk. It is uncertain if CAC scoring will be costeffective in a population-based strategy. However, it certainly helps clinicians in the aggressive management of CAD in asymptomatic patients. The CAC score is a strong predictor of CHD incidence, and provides predictive information beyond the traditional risk factors in different ethnic groups.

\section{Disclosure}

The authors report no conflicts of interest in this work.

\section{References}

1. Conroy RM, Pyorala K, Fitzgerald AP, et al. Estimation of ten-year risk of fatal cardiovascular disease in Europe: The SCORE project. Eur Heart J. 2003;24(11):987-1003.

2. Assmann G, Schulte H. The Prospective Cardiovascular Munster (PROCAM) study: Prevalence of hyperlipidemia in persons with hypertension and/or diabetes mellitus and the relationship to coronary heart disease. Am Heart J. 1988;116(6 Pt 2):1713-1724.

3. Gibbons RJ, Balady GJ, Beasley JW, et al. ACC/AHA Guidelines for Exercise Testing. A report of the American College of Cardiology/ American Heart Association Task Force on Practice Guidelines (Committee on Exercise Testing). J Am Coll Cardiol. 1997;30(1):260-311.

4. Greenland P, Smith SC Jr, Grundy SM. Improving coronary heart disease risk assessment in asymptomatic people: Role of traditional risk factors and noninvasive cardiovascular tests. Circulation. 2001;104(15): $1863-1867$ 
5. Smith SC Jr, Greenland P, Grundy SM. AHA Conference Proceedings. Prevention conference V: Beyond secondary prevention: Identifying the high-risk patient for primary prevention: Executive summary. American Heart Association. Circulation. 2000;101(1):111-116.

6. Executive Summary of The Third Report of The National Cholesterol Education Program (NCEP) Expert Panel on Detection, Evaluation, And Treatment of High Blood Cholesterol In Adults (Adult Treatment Panel III). JAMA. 2001;285(19):2486-2497.

7. Chobanian AV, Bakris GL, Black HR, et al. The Seventh Report of the Joint National Committee on Prevention, Detection, Evaluation, and Treatment of High Blood Pressure: The JNC 7 report. JAMA. 2003; 289(19):2560-2572.

8. Wilson PW, D'Agostino RB, Levy D, Belanger AM, Silbershatz H, Kannel WB. Prediction of coronary heart disease using risk factor categories. Circulation. 1998;97(18):1837-1847.

9. D’Agostino RB Sr, Grundy S, Sullivan LM, Wilson P. Validation of the Framingham coronary heart disease prediction scores: Results of a multiple ethnic groups investigation. JAMA. 2001;286(2):180-187.

10. Tunstall-Pedoe H, Kuulasmaa K, Mahonen M, Tolonen H, Ruokokoski E, Amouyel P. Contribution of trends in survival and coronary-event rates to changes in coronary heart disease mortality: 10-year results from 37 WHO MONICA project populations. Monitoring trends and determinants in cardiovascular disease. Lancet. 1999;353(9164): $1547-1557$.

11. Ehara S, Kobayashi Y, Yoshiyama M, et al. Spotty calcification typifies the culprit plaque in patients with acute myocardial infarction: An intravascular ultrasound study. Circulation. 2004;110(22): 3424-3429.

12. Beckman JA, Ganz J, Creager MA, Ganz P, Kinlay S. Relationship of clinical presentation and calcification of culprit coronary artery stenoses. Arterioscler Thromb Vasc Biol. 2001;21(10):1618-1622.

13. Rumberger JA, Simons DB, Fitzpatrick LA, Sheedy PF, Schwartz RS. Coronary artery calcium area by electron-beam computed tomography and coronary atherosclerotic plaque area. A histopathologic correlative study. Circulation. 1995;92(8):2157-2162.

14. Greenland P, Bonow RO, Brundage BH, et al. ACCF/AHA 2007 clinical expert consensus document on coronary artery calcium scoring by computed tomography in global cardiovascular risk assessment and in evaluation of patients with chest pain: A report of the American College of Cardiology Foundation Clinical Expert Consensus Task Force (ACCF/AHA Writing Committee to Update the 2000 Expert Consensus Document on Electron Beam Computed Tomography) developed in collaboration with the Society of Atherosclerosis Imaging and Prevention and the Society of Cardiovascular Computed Tomography. J Am Coll Cardiol. 2007;49(3):378-402.

15. Greenland P, Bonow RO, Brundage BH, et al. ACCF/AHA 2007 clinical expert consensus document on coronary artery calcium scoring by computed tomography in global cardiovascular risk assessment and in evaluation of patients with chest pain: A report of the American College of Cardiology Foundation Clinical Expert Consensus Task Force (ACCF/AHA Writing Committee to Update the 2000 Expert Consensus Document on Electron Beam Computed Tomography). Circulation. 2007;115(3):402-426.

16. Naghavi M, Falk E, Hecht HS, et al. From vulnerable plaque to vulnerable patient - Part III: Executive summary of the Screening for Heart Attack Prevention and Education (SHAPE) Task Force report. Am J Cardiol. 2006;98(2A):2H-15H.

17. Falk E, Shah PK, Fuster V. Coronary plaque disruption. Circulation. 1995;92(3):657-671.

18. O’Malley PG, Taylor AJ, Jackson JL, Doherty TM, Detrano RC. Prognostic value of coronary electron-beam computed tomography for coronary heart disease events in asymptomatic populations. Am J Cardiol. 2000;85(8):945-948.

19. Raggi P, Callister TQ, Shaw LJ. Progression of coronary artery calcium and risk of first myocardial infarction in patients receiving cholesterol-lowering therapy. Arterioscler Thromb Vasc Biol. 2004;24(7): $1272-1277$.
20. Greenland P, LaBree L, Azen SP, Doherty TM, Detrano RC. Coronary artery calcium score combined with Framingham score for risk prediction in asymptomatic individuals. JAMA. 2004;291(2):210-215.

21. Arad Y, Goodman KJ, Roth M, Newstein D, Guerci AD. Coronary calcification, coronary disease risk factors, C-reactive protein, and atherosclerotic cardiovascular disease events: The St Francis Heart Study. J Am Coll Cardiol. 2005;46(1):158-165.

22. Taylor AJ, Bindeman J, Feuerstein I, Cao F, Brazaitis M, O'Malley PG. Coronary calcium independently predicts incident premature coronary heart disease over measured cardiovascular risk factors: Mean three-year outcomes in the Prospective Army Coronary Calcium (PACC) project. J Am Coll Cardiol. 2005;46(5):807-814.

23. Vliegenthart R, Oudkerk M, Hofman A, et al. Coronary calcification improves cardiovascular risk prediction in the elderly. Circulation. 2005;112(4):572-577.

24. LaMonte MJ, FitzGerald SJ, Church TS, et al. Coronary artery calcium score and coronary heart disease events in a large cohort of asymptomatic men and women. Am J Epidemiol. 2005;162(5):421-429.

25. Arad Y, Spadaro LA, Goodman K, Newstein D, Guerci AD. Prediction of coronary events with electron beam computed tomography. $J \mathrm{Am}$ Coll Cardiol. 2000;36(4):1253-1260.

26. Kondos GT, Hoff JA, Sevrukov A, et al. Electron-beam tomography coronary artery calcium and cardiac events: A 37-month follow-up of 5635 initially asymptomatic low- to intermediate-risk adults. Circulation. 2003;107(20):2571-2576.

27. Bild DE, Detrano R, Peterson D, et al. Ethnic differences in coronary calcification: The Multi-Ethnic Study of Atherosclerosis (MESA). Circulation. 2005;111(10):1313-1320.

28. Detrano R, Guerci AD, Carr JJ, et al. Coronary calcium as a predictor of coronary events in four racial or ethnic groups. N Engl J Med. 2008; 358(13):1336-1345.

29. O'Rourke RA, Brundage BH, Froelicher VF, et al. American College of Cardiology/American Heart Association Expert Consensus document on electron-beam computed tomography for the diagnosis and prognosis of coronary artery disease. Circulation. 2000;102(1):126-140.

30. O'Rourke RA, Brundage BH, Froelicher VF, et al. American College of Cardiology/American Heart Association Expert Consensus Document on electron-beam computed tomography for the diagnosis and prognosis of coronary artery disease. J Am Coll Cardiol. 2000;36(1):326-340.

31. Guerci AD, Spadaro LA, Goodman KJ, et al. Comparison of electron beam computed tomography scanning and conventional risk factor assessment for the prediction of angiographic coronary artery disease. J Am Coll Cardiol. 1998;32(3):673-679.

32. Rosen BD, Fernandes V, McClelland RL, et al. Relationship between baseline coronary calcium score and demonstration of coronary artery stenoses during follow-up MESA (Multi-Ethnic Study of Atherosclerosis). JACC Cardiovasc Imaging. 2009;2(10):1175-1183.

33. Schmermund A, Bailey KR, Rumberger JA, Reed JE, Sheedy PF 2nd, Schwartz RS. An algorithm for noninvasive identification of angiographic three-vessel and/or left main coronary artery disease in symptomatic patients on the basis of cardiac risk and electron-beam computed tomographic calcium scores. JAm Coll Cardiol. 1999;33(2): 444-452.

34. Budoff MJ, Diamond GA, Raggi P, et al. Continuous probabilistic prediction of angiographically significant coronary artery disease using electron beam tomography. Circulation. 2002;105(15):1791-1796.

35. Haberl R, Becker A, Leber A, et al. Correlation of coronary calcification and angiographically documented stenoses in patients with suspected coronary artery disease: Results of 1,764 patients. $\mathrm{J} \mathrm{Am} \mathrm{Coll} \mathrm{Cardiol.}$ 2001;37(2):451-457.

36. Nieman K, Galema TW, Neefjes LA, et al. Comparison of the value of coronary calcium detection to computed tomographic angiography and exercise testing in patients with chest pain. Am J Cardiol. 2009;104(11):1499-1504.

37. Raggi P, Callister TQ, Cooil B, et al. Identification of patients at increased risk of first unheralded acute myocardial infarction by electron-beam computed tomography. Circulation. 2000;101(8):850-855. 
38. Wong ND, Hsu JC, Detrano RC, Diamond G, Eisenberg H, Gardin JM. Coronary artery calcium evaluation by electron beam computed tomography and its relation to new cardiovascular events. Am J Cardiol. 2000;86(5):495-498.

39. Tatum JL, Jesse RL, Kontos MC, et al. Comprehensive strategy for the evaluation and triage of the chest pain patient. Ann Emerg Med. 1997; 29(1):116-125.

40. Reilly BM, Evans AT, Schaider JJ, et al. Impact of a clinical decision rule on hospital triage of patients with suspected acute cardiac ischemia in the emergency department. JAMA. 2002;288(3):342-350.

41. McLaughlin VV, Balogh T, Rich S. Utility of electron beam computed tomography to stratify patients presenting to the emergency room with chest pain. Am J Cardiol. 1999;84(3):327-328, A328.

42. Georgiou D, Budoff MJ, Kaufer E, Kennedy JM, Lu B, Brundage BH. Screening patients with chest pain in the emergency department using electron beam tomography: A follow-up study. J Am Coll Cardiol. 2001;38(1):105-110.

43. Simons DB, Schwartz RS, Edwards WD, Sheedy PF, Breen JF, Rumberger JA. Noninvasive definition of anatomic coronary artery disease by ultrafast computed tomographic scanning: A quantitative pathologic comparison study. J Am Coll Cardiol. 1992; 20(5):1118-1126.

44. Rumberger JA, Schwartz RS, Simons DB, Sheedy PF 3rd, Edwards WD, Fitzpatrick LA. Relation of coronary calcium determined by electron beam computed tomography and lumen narrowing determined by autopsy. Am J Cardiol. 1994;73(16):1169-1173.

45. Kaufmann RB, Peyser PA, Sheedy PF, Rumberger JA, Schwartz RS. Quantification of coronary artery calcium by electron beam computed tomography for determination of severity of angiographic coronary artery disease in younger patients. J Am Coll Cardiol. 1995; 25(3):626-632.

46. He ZX, Hedrick TD, Pratt CM, et al. Severity of coronary artery calcification by electron beam computed tomography predicts silent myocardial ischemia. Circulation. 2000;101(3):244-251.

47. Berman DS, Wong ND, Gransar H, et al. Relationship between stressinduced myocardial ischemia and atherosclerosis measured by coronary calcium tomography. J Am Coll Cardiol. 2004;44(4):923-930.

48. Waters D, Higginson L, Gladstone P, et al. Effects of monotherapy with an HMG-CoA reductase inhibitor on the progression of coronary atherosclerosis as assessed by serial quantitative arteriography. The Canadian Coronary Atherosclerosis Intervention Trial. Circulation. 1994;89(3):959-968.

49. Schmermund A, Baumgart D, Mohlenkamp S, et al. Natural history and topographic pattern of progression of coronary calcification in symptomatic patients: An electron-beam CT study. Arterioscler Thromb Vasc Biol. 2001;21(3):421-426.
50. Budoff MJ, Lane KL, Bakhsheshi H, et al. Rates of progression of coronary calcium by electron beam tomography. Am J Cardiol. 2000; 86(1):8-11.

51. Maher JE, Bielak LF, Raz JA, Sheedy PF 2nd, Schwartz RS, Peyser PA. Progression of coronary artery calcification: A pilot study. Mayo Clin Proc. 1999;74(4):347-355.

52. Mao S, Bakhsheshi H, Lu B, Liu SC, Oudiz RJ, Budoff MJ. Effect of electrocardiogram triggering on reproducibility of coronary artery calcium scoring. Radiology. 2001;220(3):707-711.

53. Raggi P, Cooil B, Shaw LJ, et al. Progression of coronary calcium on serial electron beam tomographic scanning is greater in patients with future myocardial infarction. Am J Cardiol. 2003;92(7):827-829.

54. Raggi P, Cooil B, Ratti C, Callister TQ, Budoff M. Progression of coronary artery calcium and occurrence of myocardial infarction in patients with and without diabetes mellitus. Hypertension. 2005; 46(1):238-243.

55. Callister TQ, Raggi P, Cooil B, Lippolis NJ, Russo DJ. Effect of HMG-CoA reductase inhibitors on coronary artery disease as assessed by electron-beam computed tomography. NEngl J Med. 1998; 339(27): 1972-1978.

56. Budoff MJ, Shavelle DM, Lamont DH, et al. Usefulness of electron beam computed tomography scanning for distinguishing ischemic from nonischemic cardiomyopathy. J Am Coll Cardiol. 1998;32(5): 1173-1178.

57. Agatston AS, Janowitz WR, Hildner FJ, Zusmer NR, Viamonte M Jr, Detrano R. Quantification of coronary artery calcium using ultrafast computed tomography. J Am Coll Cardiol. 1990;15(4):827-832.

58. McClelland RL, Chung H, Detrano R, Post W, Kronmal RA. Distribution of coronary artery calcium by race, gender, and age: Results from the Multi-Ethnic Study of Atherosclerosis (MESA). Circulation. 2006;113(1):30-37.

59. Hunold P, Vogt FM, Schmermund A, et al. Radiation exposure during cardiac CT: Effective doses at multi-detector row CT and electron-beam CT. Radiology. 2003;226(1):145-152.

60. Gerber TC, Carr JJ, Arai AE, et al. Ionizing Radiation in Cardiac Imaging: A Science Advisory From the American Heart Association Committee on Cardiac Imaging of the Council on Clinical Cardiology and Committee on Cardiovascular Imaging and Intervention of the Council on Cardiovascular Radiology and Intervention. Circulation. 2009;119(7):1056-1065.

61. Berrington de Gonzalez A, Mahesh M, Kim KP, et al. Projected cancer risks from computed tomographic scans performed in the United States in 2007. Arch Intern Med. 2009;169(22):2071-2077.
Vascular Health and Risk Management

\section{Publish your work in this journal}

Vascular Health and Risk Management is an international, peerreviewed journal of therapeutics and risk management, focusing on concise rapid reporting of clinical studies on the processes involved in the maintenance of vascular health; the monitoring, prevention and treatment of vascular disease and its sequelae; and the involvement of

\section{Dovepress}

metabolic disorders, particularly diabetes. This journal is indexed on PubMed Central and MedLine. The manuscript management system is completely online and includes a very quick and fair peer-review system, which is all easy to use. Visit http://www.dovepress.com/ testimonials.php to read real quotes from published authors. 